\title{
Comparison the Protective Effects of L-Carnitine and Acetyl L- Carnitine on Blood Glucose and Lipid Peroxidation Level in Diabetic Rats
}

Hajinezhad M.R.* PhD, Hajian Sh.1 DVM, Saghayei S.1 DVM, Samzadeh-Kermani A.R. ${ }^{2}$ PhD, Nabavi R. ${ }^{3}$ PhD

*Basic Science Department, Veterinary Medicine Faculty, University of Zabol, Zabol, Iran 1Basic Science Department, Veterinary Medicine Faculty, University of Zabol, Zabol, Iran ${ }^{2}$ Chemistry Department, Basic Science Faculty, University of Zabol, Zabol, Iran

${ }^{3}$ Pathobiology Department, Veterinary Faculty, University of Zabol, Zabol, Iran

\begin{abstract}
Aims: New medications with less side-effect are increasingly noticed now a day. L-Carnitine and Acetyl L-Carnitine reduce the secondary side-effects of Type I diabetes. The aim of this study was to investigate the effects of oral administration of the materials on the blood glucose and the lipid per-oxidation of the liver and brain tissues in the diabetic rats.

Materials \& Methods: In the experimental study, 50 male Wistar rats were studied. The rats were randomly divided into five groups including control (the healthy rats), negative control (the diabetic rats), and three treatment diabetic groups. The diabetic groups received $110 \mathrm{mg} / \mathrm{Kg}$ alloxan via injection to become diabetic. The treatment groups received L-Carnitine, Acetyl L-Carnetine, and LCarnetine with Acetyl L-Carnetine $(300 \mathrm{mg} / \mathrm{Kg}$ ) as gavage for 30 days. The lipid per-oxidation, the serum glucose, the lipid profile, and the liver enzymes were measured at the end of the experiment. Data was analyzed using one-way ANOVA followed by Tukey complementary test.

Findings: The fasting blood concentration, triglyceride, cholesterol, creatinine, the serum liver enzymes, and the level of the liver tissue malondialdehyde significantly decreased in treatment diabetic group than diabetic group without any treatment, while HDL level increased as well $(\mathrm{p}<0.05)$. The brain tissue malondialdehyde and the serum HDL decreased and increased due to the administration of Acetyl L-Carnitine, respectively. Nevertheless, it affected no other parameter significantly. The positive effects of L-Carnitine were reduced by the administration of Acetyl L-Carnitin with L-Carnitine.

Conclusion: The administration of L-Carnitine further reduces the secondary side-effects of diabetes than Acetyl L-Carnitine. In addition, simultaneous administration of the materials is not recommended.
\end{abstract}

\section{Keywords}

Diabetes Mellitus [http://www.ncbi.nlm.nih.gov/mesh/68003920];

L-Carnitine [http://www.ncbi.nlm.nih.gov/mesh/68002331];

Acetyl L-Carnitine [http://www.ncbi.nlm.nih.gov/mesh/68000108];

Rats [http://www.ncbi.nlm.nih.gov/mesh/68051381]

\footnotetext{
* Corresponding Author

Tel: +985422323567

Fax: +985422323567

Address: Basic Science Department, Veterinary Medicine Faculty, University of Zabol, Bonjar Ave, Zabol, Iran. Postal Code: $98613-35856$

hajinezhad@uoz.ac.ir

Received: October 24, $2015 \quad$ Accepted: May 10, 2016 ePublished: June 30, 2016
} 
.

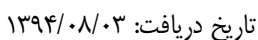

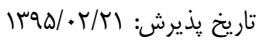

"نويسنده مسئول: hajinezhad@uoz.ac.ir
مقايسه اثر حفاظتى ال- كارنيتين و استيل الكارنيتين بر سطح كلوكز سرم و يراكسيداسيون

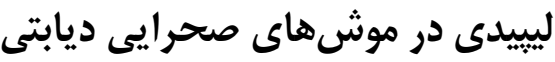

\section{مقدمه}

ديابت نوع اول يكى از شايعترين بيمارىهاى غدد درونريز است.

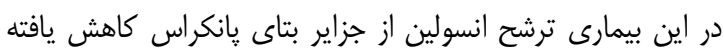

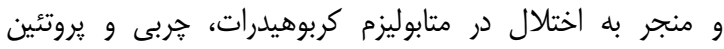

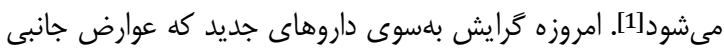

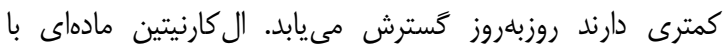
ساختار مشابه اسيدآمينه و عملكرد شبيه ويتامين است. ال كارنين إنيتين

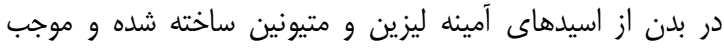

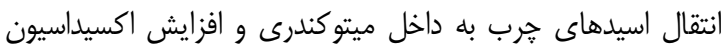

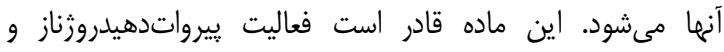

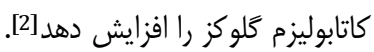
مطالعات انجامشده در انسان نشاندهنده اثر آنتىاكسيدانى قوى

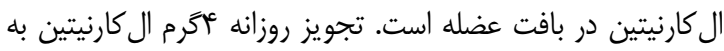

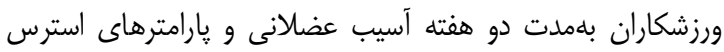

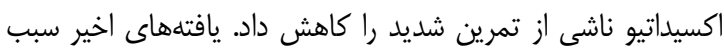

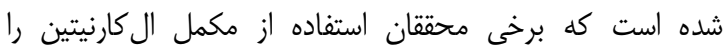

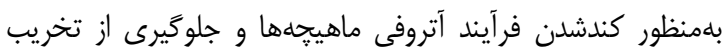

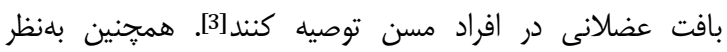

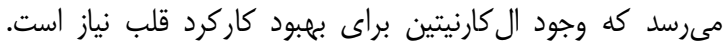

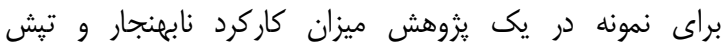

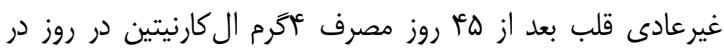

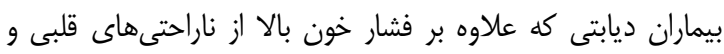

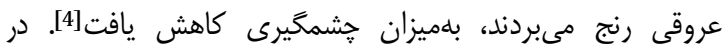

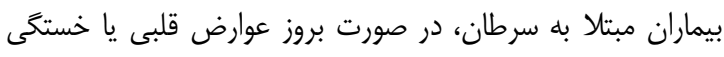

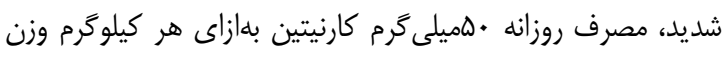

بدن توصيه شده است [5].

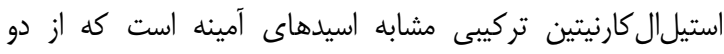

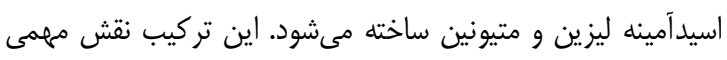

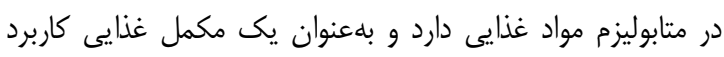

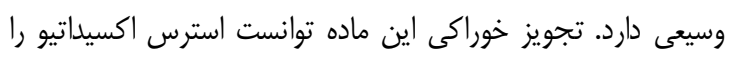

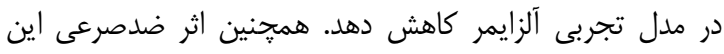

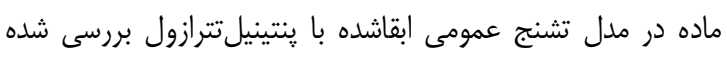

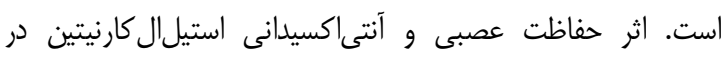

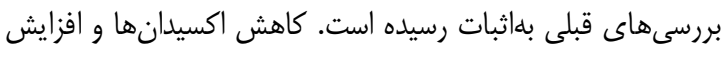

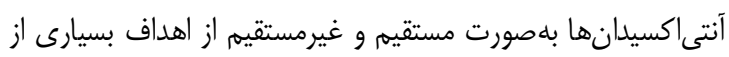

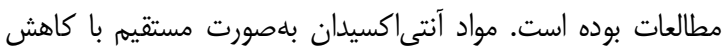
راديكالهاى آزاد تا حدودى در تنظيم تعادل مواد آنتىاكسيدان - آنسي

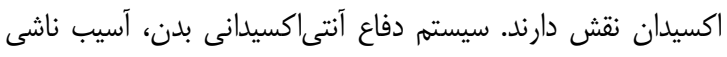

PhD محمدر الجا حاجىنزاد

كَروه علوم يايه، دانشكده داميزشكى، دانشكاه زابل، زابل، ايران

شقايق حاجيان شهرى DVM

كروه علوم پِايه، دانشكده داميزشكى، دانشكاه زابل، زابل، ايران

سميرا سقايى DVM

كَروه علوم بايا،، دانشكده داميزشكى، دانشكاه زابل، زابل، ايران

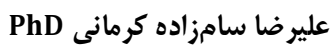

كروره شيمى، دانشكده علوم، دانشاء زابل، زابل، ايران

رضا نبوى PhD

كَروه ياتوبيولوزى، دانشكده داميزشكى، دانشكاه زابل. زابل، ايران

جكيده

الهداف: امروزه كرايش بهسوى داروهاى جديد كه عوارض جانبى كمترى

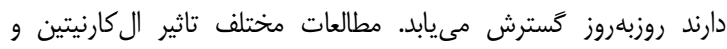

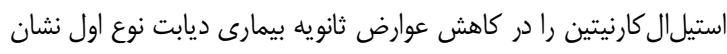

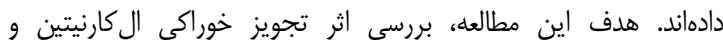

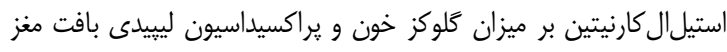

و كبد در رتهاى ديابتى بود.

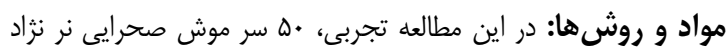

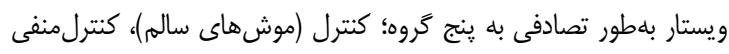

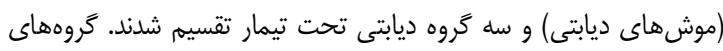

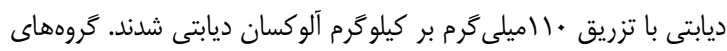

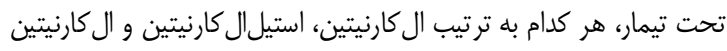

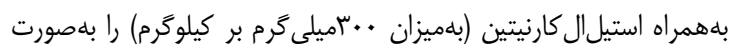

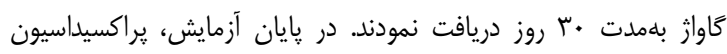

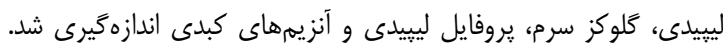

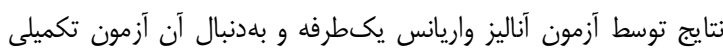
توكى تحليل شدند.

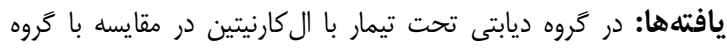

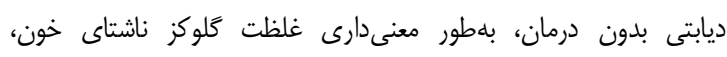

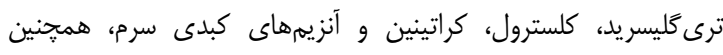

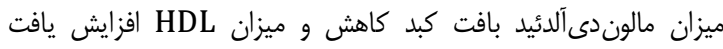

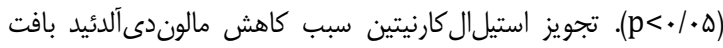

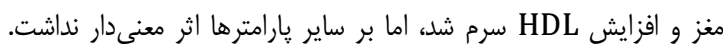

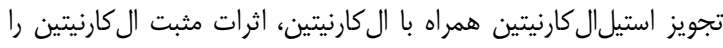

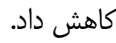

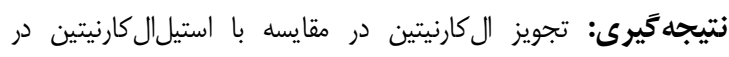

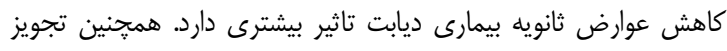

همزمان اين دو ماده توصيه نمى شوارد.

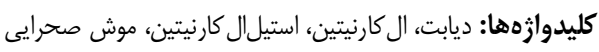




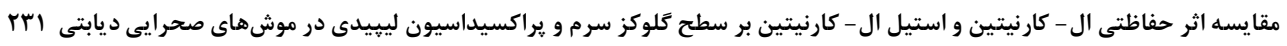

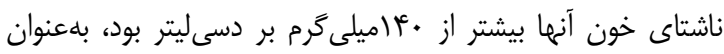

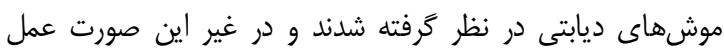

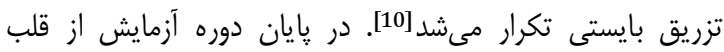

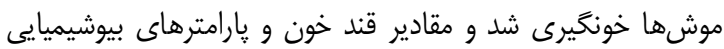
سرم اندازميرى شد. براى بلددستآوردن مقادير سرمى كلسترول توتال، ترى كليسريد، HDL-C

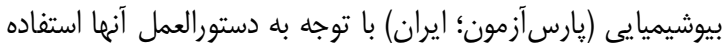

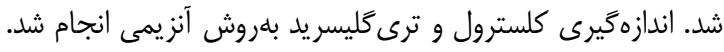

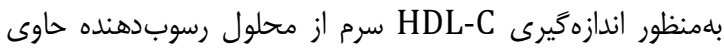

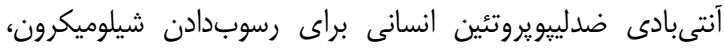
LDL-C

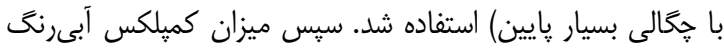

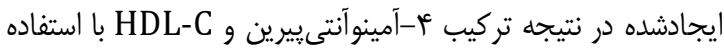

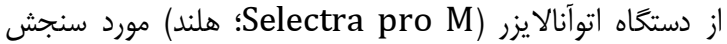

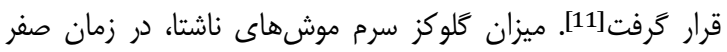

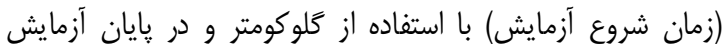

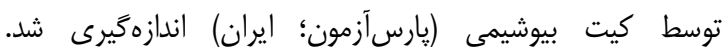
آنزيمهاى $\quad$ ALT $\quad$ AST

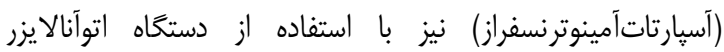
و و براساس دستورالعمل كيتهاى (Selectra pro M)

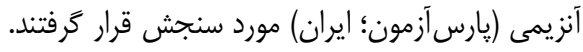

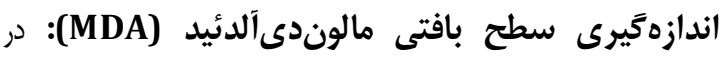

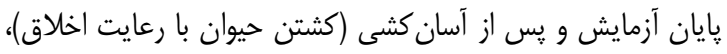

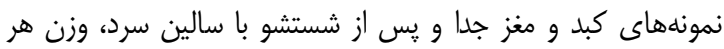

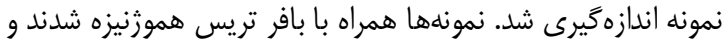

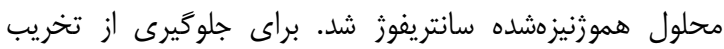

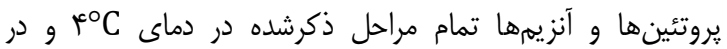

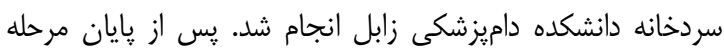

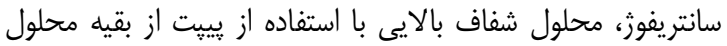

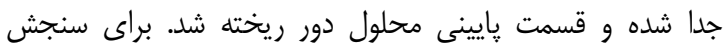
ميزان مالوندى آلدئيد بافتى از محلول شفاف دافئ بالائيى استفاده شد.

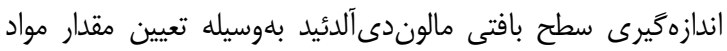
واكنشدهنده با تيوباربيتوريكاسيد و دستورالعمل كيت (انزانشيمى؛ إنشي؛

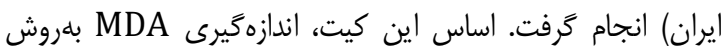

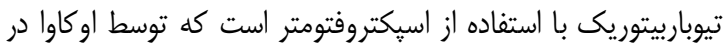
سال 1997 شرح داده شد [1/]. براساس دستورالعمل كيت،

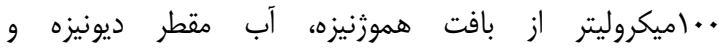

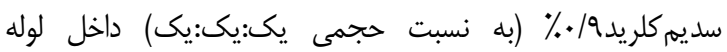

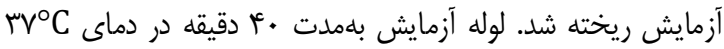

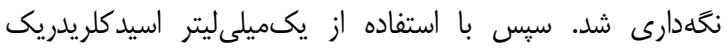

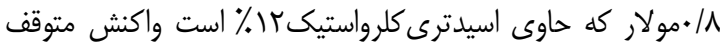

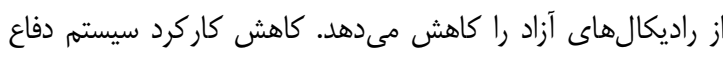
آنتىاكسيدانى و افزايش توليد راديكالهاى آزادا، شرايط را براى برائ بروز

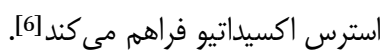

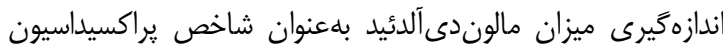

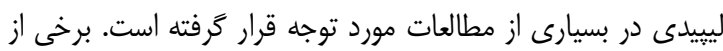

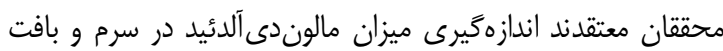
كبد مىتواند بلعنوان يكى از شاخصهان استرس اكسيداتيو مانيون

استفاده شود][7]. با توجه به خواص آنتىاكسيدانى الكارنيتين و استيلال كارنيتين، اين مطالعه با هدف بررسى اثر تجويز خوراكى اين دو ماده بر بر ميزانين

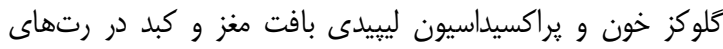

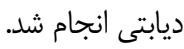

\section{مواد و روشها}

اين مطالعه تجربى روى •D سر موش صحرايى نر نزاد ويستار با

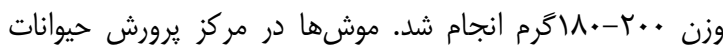
آزمايشكاهى دانشكده داميزشكى دانشكاه زابل در شرايط استاندارد

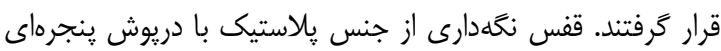

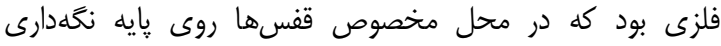
مىشد. قفسها هر f أ روز يكبار تعويض و تميز مى مشدند. حيوانات به آب و غذاى مخصوص موش (شركت جوانه خراسان؛ ايران)

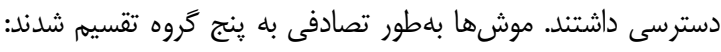

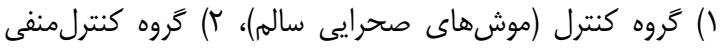

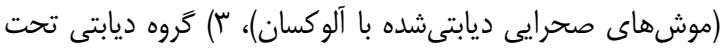

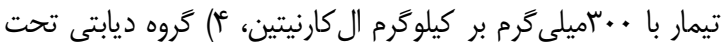

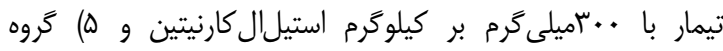

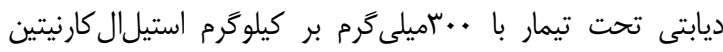

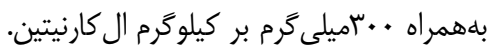

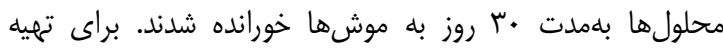

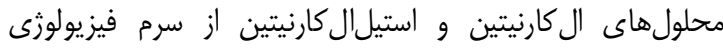

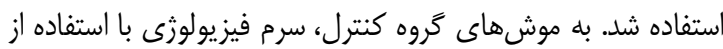

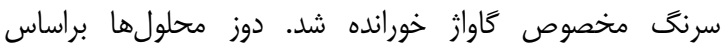

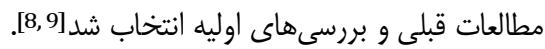

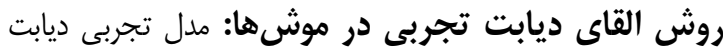

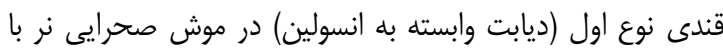
تزريق درونصفاقى آلوكسان ايجاد شد. يودر آلوكسان (سيخما؛

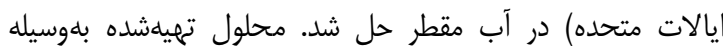
سرنخ انسولين با دوز • •الميلى

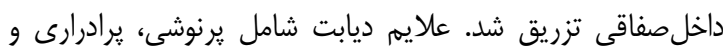

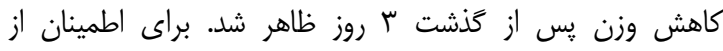

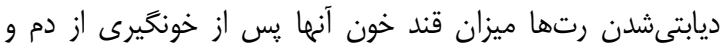
توسط دستكاه كلوكومتر كنترل شد. در صورتى كه سطح خلوكز 
ترى گليسريد و كلسترول خون نداشت، اما ميزان HDL را بلطور

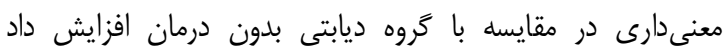

$$
\text { . (p<+/.+1) }
$$

تجويز ال كارنيتين، ميزان كراتينين سرم را در مقايسه با كَروه كنترل

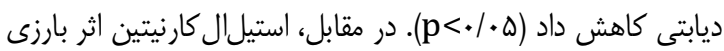

$$
\text { بر كراتينين سرم نداشت. }
$$

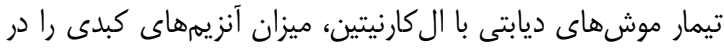

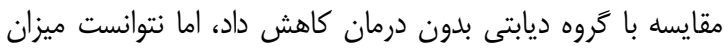

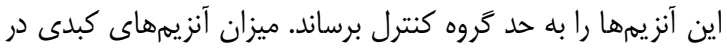

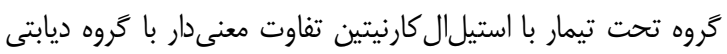

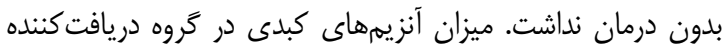

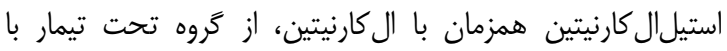

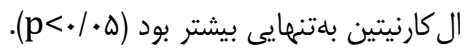

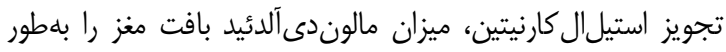

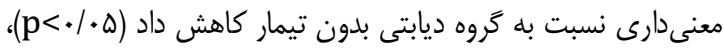

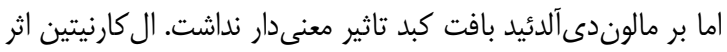
معنى دارى بر يراكسيداسيون لييبيدى بافت مغز نداشت، اما ميزان

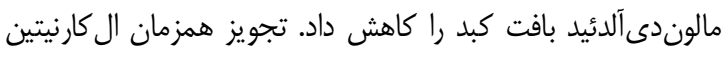

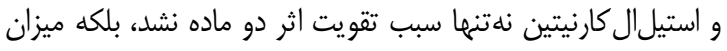

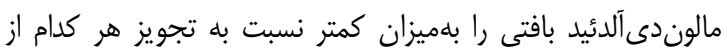
مواد بلتنهايى كاهش داد (جدول ().

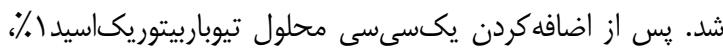

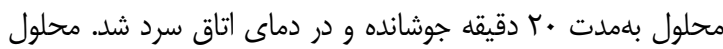

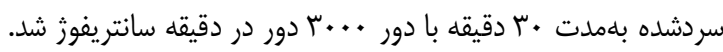

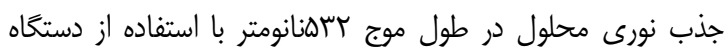

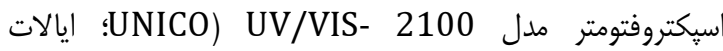

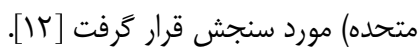
تجزيه و تحليل آمارى دادهها: تمام نتايج بهصورت ميانخين

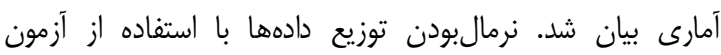

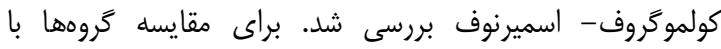

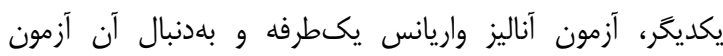
تكميلى توكى مورد استفاده قرار ترفت.

يافتهها

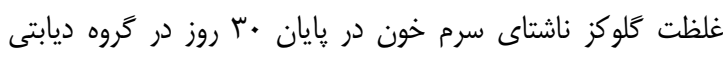

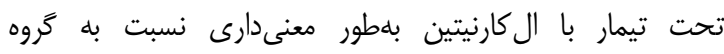

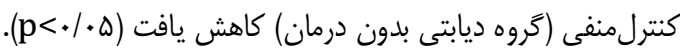

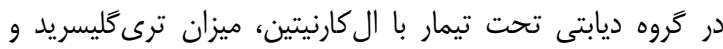

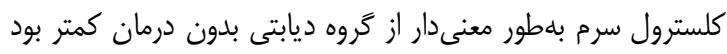

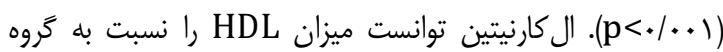

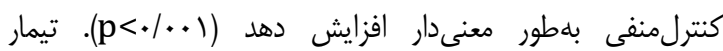
رتهاى ديابتى با استيلالكارنيتين اثر معنىدارى بر دهر ميزان

\begin{tabular}{|c|c|c|c|c|c|}
\hline كروه ديابتى + ال كارنيتين و & استروه ديابتى+ & ترووه ديابتى+ الركارنيتين & 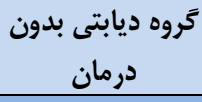 & كروه كنترل & متغير هاى مورد بر رسى \\
\hline & & & & & 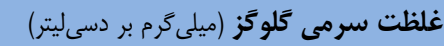 \\
\hline$\Lambda F / \Delta \tau \pm \Delta / \cdot 1$ & $Q \cdot|r| \pm \Delta / r \mid$ & $M N \cdot q \pm \varepsilon / K_{1}$ & $\Lambda F / F i \pm f / V I$ & $N N / \Delta \cdot \pm F / T_{q}$ & در روز صفر \\
\hline$r \cdot \varepsilon / \Lambda \cdot \pm \mid l / K r$ & $19 N / 4+2 \pm 9 / 14$ & 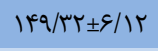 & $t \cdot 1 / 4 t \pm T / R T$ & $9 Y / I V \pm F / 1$ & 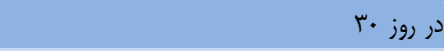 \\
\hline & & & & & يار امترهاى بيوشيميايى سرم \\
\hline$|r V /| r \pm|| / \mu \mid$ & $\mid r V / \cdot \Lambda \pm V / T$. & $Q \S / \cdot \Upsilon \pm \Delta / / \varepsilon$ & $|r N / \Lambda \cdot \pm \Delta| \cdot \varphi$ & १) $/ \Delta \cdot \pm V / \Delta F$ & كلسترول (ميلى كرم بر دسىليتر) \\
\hline$|V q / 4 \cdot \pm| r / \cdot 9$ & $|M N / 9 \cdot \pm V / M|$ & $11 V / \Delta \cdot \pm F / I \varepsilon$ & $191 / r Y \pm \mid V / 1$. & $11 \cdot / 2 \cdot \pm N / 2$ & ترى گليسريد (ميلى گرم بر دسىليتر) \\
\hline$|r / r| \pm r / F$ & $r V / Q \varepsilon \pm \Delta / r$. & $r \Delta / \Lambda T_{ \pm} r / q \Lambda$ & $8 / \Lambda \cdot \pm 1 / \wedge 9$ & $r N / \Delta \cdot \pm r / V^{e}$ & HDL-C \\
\hline $199 / \Delta \cdot \pm 1 \% / \cdot$. & $19 N / 1 \cdot \pm N / 84$ & $\mid \varsigma V / \Gamma \cdot \pm \Phi / 1 \varphi$ & $r I I / r \cdot \pm \mid Q / I F$ & $1 \cdot 1 / r \cdot \pm \Delta / 1$ & AST \\
\hline$T K T / r \cdot \pm I T / \cdot 9$ & $r T K / V \cdot \pm I I / r$. & $\mid \varepsilon N / \Lambda \cdot \pm N / \cdot$ & $r \Delta F / \tau+ \pm F / .$. & 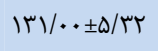 & (واحد بر ليتر) ALT \\
\hline $1 / \Delta \cdot \pm \cdot / / 1$ & $V / \Delta F \pm \cdot / T V$ & $1 / 8 \cdot \pm \cdot / 1 \Lambda$ & $t / N t_{ \pm} \cdot / 4 t$ & $|/ \Delta| \pm \cdot / T 1$ & كراتينين (ميلى گرم بر دسىليتر) \\
\hline \multicolumn{6}{|r|}{ ميزان مالوندى آلدئيد (نانومول بر ميلى } \\
\hline$|r / F| \pm 1 / \cdot 9$ & $q / F \cdot \pm 1 / \Delta F$ & $\mid T / T \cdot \pm \cdot / \Lambda t$ & $\mid r / F \cdot \pm 1 / \cdot \kappa^{f}$ & $N / \& \cdot \pm \cdot / V$ & 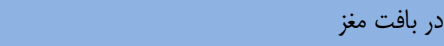 \\
\hline$V / \Lambda \cdot \pm 1 / \cdot \cdot$ & $V / T \cdot \pm \cdot / V \cdot$ & $\Delta / 1 \cdot \pm \cdot / / \mu$ & $N / 9 \cdot \pm \cdot / \mathrm{V}$ & $0 / 8 \cdot \pm \cdot / 1$. & 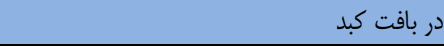 \\
\hline
\end{tabular}

جدول () مقايسه غلظت كلوكز ناشتا، پارامترهاى بيوشيميايى سرم و ميزان مالوندى آلدئيد بافت مغز و كبد موشهاى صحرايى در گروههاى آزمايشى

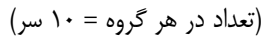

ATP است. اين ماده با افزايش انتشار تسهيلشده كلوكز به درون

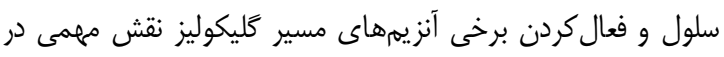

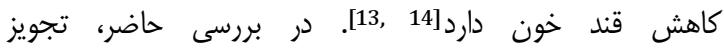
استيلالكارنيتين اثر معنىدارى بر ميزان قند خون نداشت. تجويز
نتايج اين بررسى نشان داد ال كارنيتين اثر معنىدارى بر كاهش قند

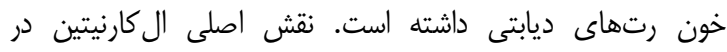
ميتوكندرى تسريع فرآيند اكسيداسيون اسيدهاى خرب إبل براى توليد دوره זr، شماره ז، تابستان هوسו فصلنامه افق دانش 


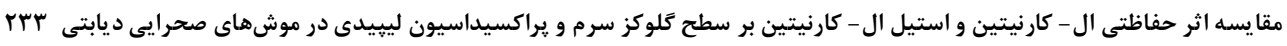

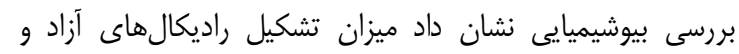

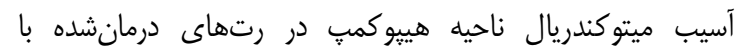

ال كارنيتين بلهور معنى دارى كمتر از گروه بلدون تيمار بود [23].

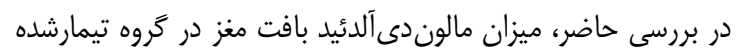

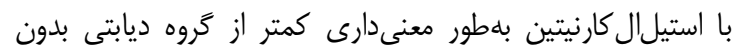
تيمار بود. اين يافته با نتايج مطالعه ليو و همكاران [16] و كاور و ودئين همكاران[24] همسو است. بلنظر مىرسد افزايش انتقال اسيدهاى ئس

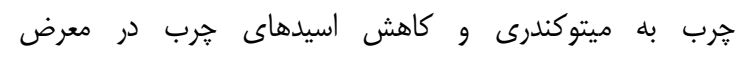
يراكسيداسيون، دليل اصلى كاهش مالوندى آلدئيد مغز باشد.

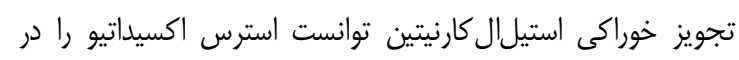

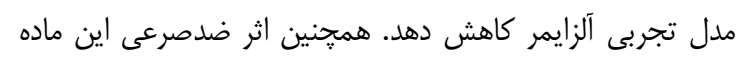

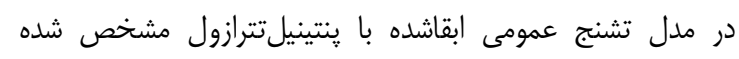

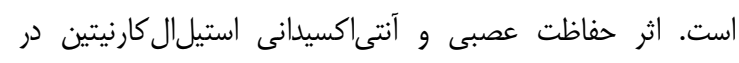
بررسىهاى قبلى بهاثبات رسيده است. استيلال كارنيتين مىتواند

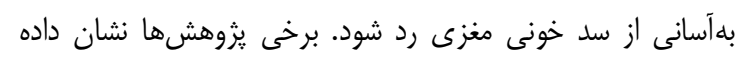

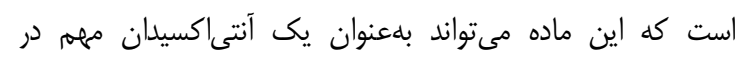
رزيمهاى غذايى استفاده شود. تجويز استيلال كارنتين سبب افزايش ماند

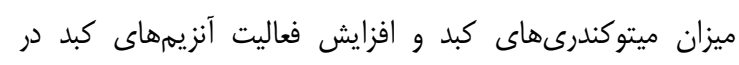

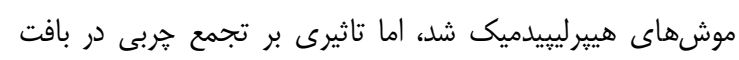

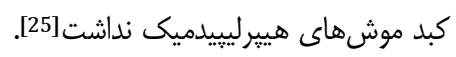

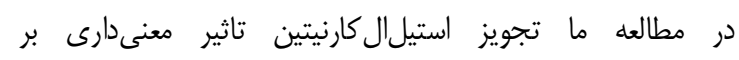
يراكسيداسيون ليييدى بافت كبد نداشت. استيلال كارنيتين نتوانست

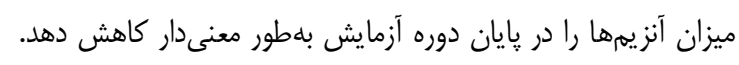

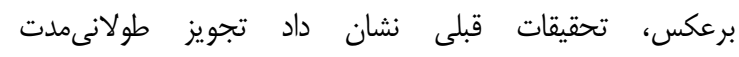

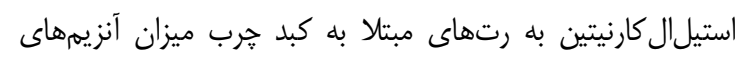

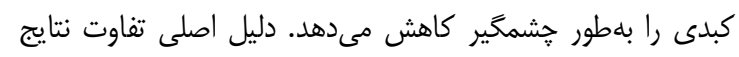
اين دو مطالعه به دوره زمانى تجويز استيلال كارنيتين مربوط است.

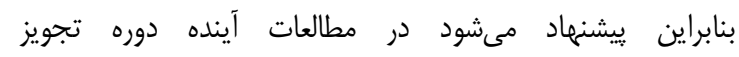

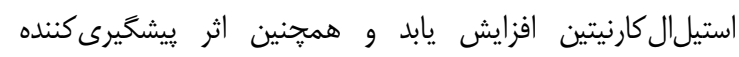

استيلال كارنيتين بررسى شود.

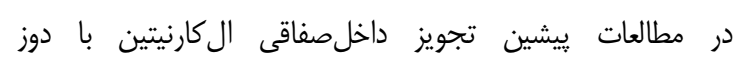

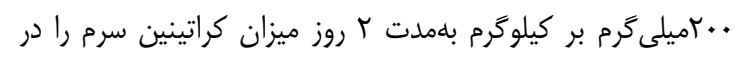

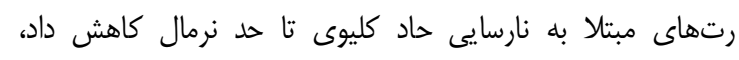

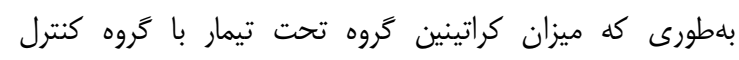

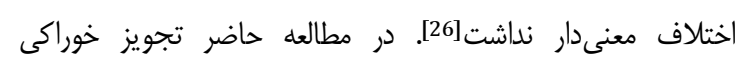

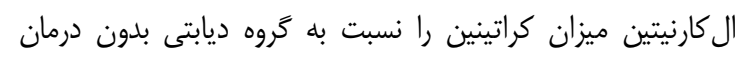

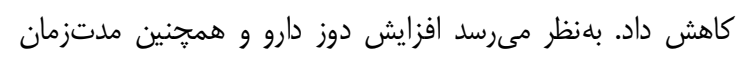

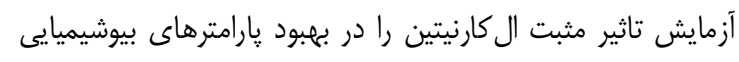

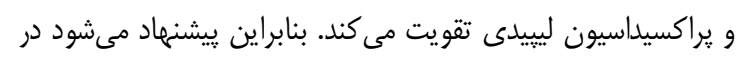

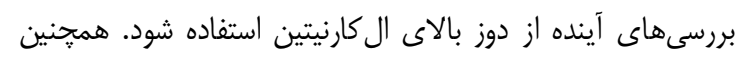
ييشنهاد مىشود در بررسىهاى بعدى مدتزمان تجويز ال كارنيتين

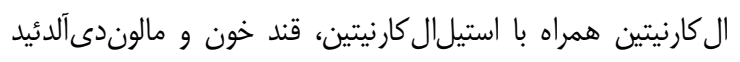
بافت كبد را بلميزان كمتر (در مقايسه با تجويز الكارنيتين

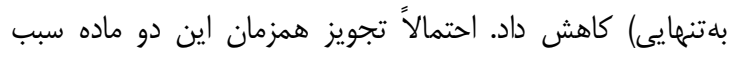

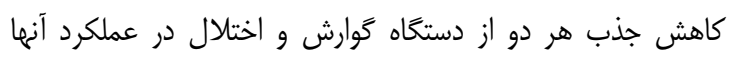

مىشود، هر جند اثبات اين مسئله نيازمند تحقيقات بيشتر است.

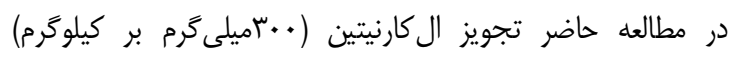
توانست ميزان مالوندى آلدئيد بافت كبد را بلهعنوان شاخص مهرئم

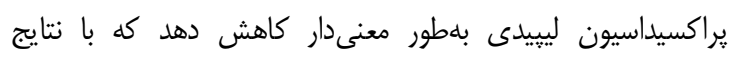

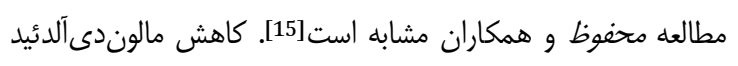

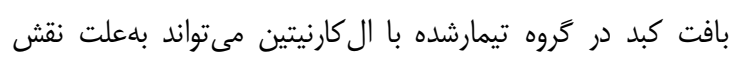

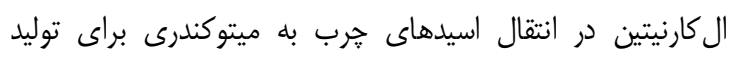

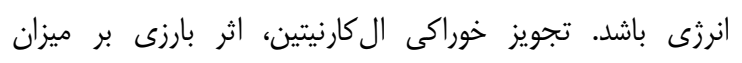

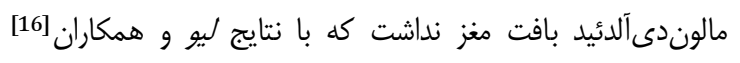

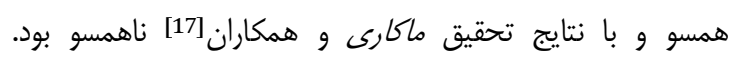

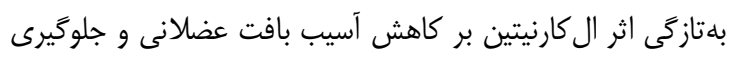

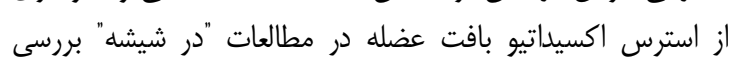
شده است. مواجهه بافت عضلانى با ال كارنيتين سبب تسريع فرآيند

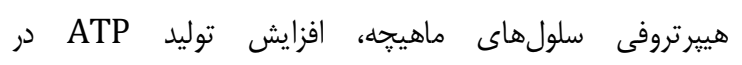
ميتوكندرىها و كاهش شاخصهاى مرتبط با استرس اكسيداتيو بافت عضله مىشود[18]. همجنين تجويز خوراكى ال كارنيتين با دوز

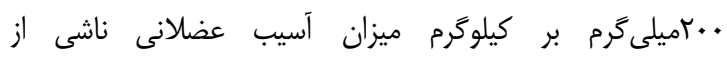
تتراكلروركربن را در بافت عضله رتهاى سالم كاهش داد[19]. افزايش HDL همراه با كاهش ترى تليسريد و كلسترول سرم نشاندهنده اثرات مثبت ال كارنيتين بر يروفايل ليييدى است. علاوه بر اين، ميزان آنزيمهاى كبدى در زروه تيمارشده با ال كارنيتين

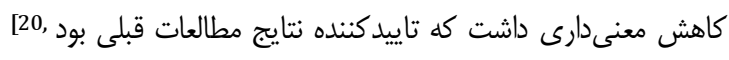

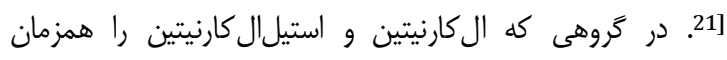

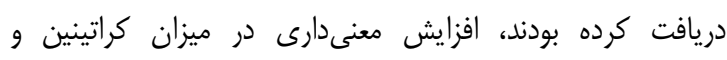

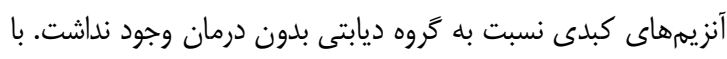

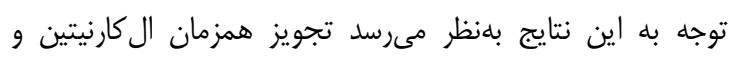
استيلال كارنيتين اثر توكسيك ندارد.

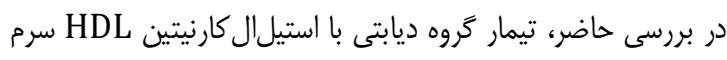

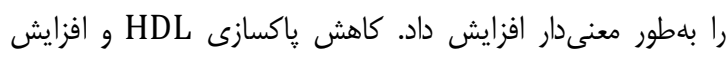
فعاليت لييويروتئين ليياز مىتواند دليل اين اثر باشد [22].

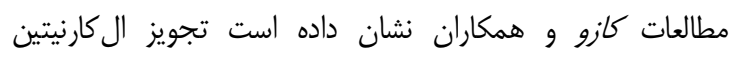

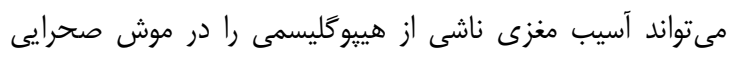

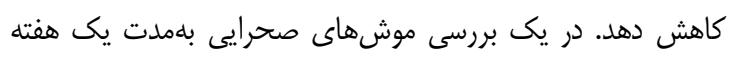

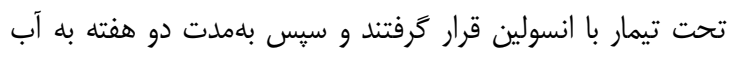

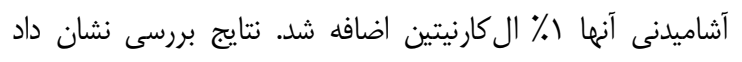
تجويز الكارنيتين سبب بهبود حافظه فضايى و كاهش رفتار

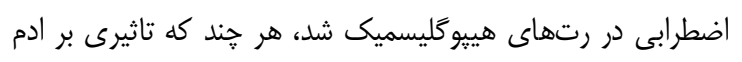

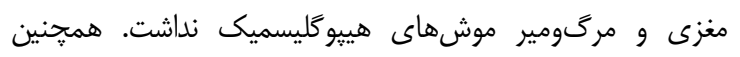


diabetes and its complications. Biomed Pharmacother. 2005;59(7):365-73.

7- Chen J, Zeng L, Xia T, Li S, Yan T, Wu S, et al. Toward a biomarker of oxidative stress: A fluorescent probe for exogenous and endogenous malondialdehyde in living cells. Anal Chem. 2015;87(16):8052-6.

8- Shaker ME, Houssen M, Abo-Hashem EM, Ibrahim TM. Comparison of vitamin E, L-carnitine and melatonin in ameliorating carbon tetrachloride and diabetes induced hepatic oxidative stress. J Physiol Biochem. 2009;65(3):225-33.

9- Petruzzella V, Baggetto LG, Penin F, Cafagna F, Ruggiero FM, Cantatore P, et al. In vivo effect of acetyl-Lcarnitine on succinate oxidation, adenine nucleotide pool and lipid composition of synaptic and non-synaptic mitochondria from cerebral hemispheres of senescent rats. Arch Gerontol Geriatr. 1992;14(2):131-44.

10- Hajinezhad MR, Davari SA, Esmaeel Zadeh S, Miri HR, Akbari M. Protective effect of hydro alcoholic extract from Prosopis farcta leaves on lipid peroxidation of serum and liver tissue in diabetic rats. J North Khorasan Univ Med Sci. 2015;7(2):267-78. [Persian]

11- Ashraf H, Heydari R, Nejati V, Ilkhanipoor $M$. Preventive effect of berberis integerrima on the serum levels of glucose and lipids in streptozotocin (STZ)induced diabetes in rats. J Fasa Univ Med Sci. 2012;2(3):148-55. [Persian]

12- Ohkawa H, Ohishi N, Yagi K. Assay for lipid peroxides in animal tissues by thiobarbituric acid reaction. Anal Biochem. 1979;95(2):351-8.

13- Hajinezhad MR, Esmaeel Zadeh Bahabadi S, Miri HR, Davari SA, Darvish Sargazi M. Effect of hydroalcoholic extract of Prosopis farcta pod on liver histopathology and malondialdehyde level in streptozotocin diabetic rats. Horizon Med Sci. 2015;21(1):31-6. [Persian]

14- Yano H, Oyanagi E, Kato Y, Samejima Y, Sasaki J, Utsumi K. L-carnitine is essential to beta-oxidation of quarried fatty acid from mitochondrial membrane by PLA(2). Mol Cell Biochem. 2010;342(1-2):95-100.

15- Mahfouz MH, Ghanem HM, Mohamed MA. Therapeutic effect of L-carnitine on sialic acid, soluble Fas (sFas) and other biochemical variables in hyperinsulinemic rats. Life Sci J. 2009;6(2):76-84.

16- Liu J, Head E, Kuratsune H, Cotman CW, Ames BN. Comparison of the effects of L-carnitine and acetyl-Lcarnitine on carnitine levels, ambulatory activity, and oxidative stress biomarkers in the brain of old rats. Ann N Y Acad Sci. 2004;1033:117-31.

17- Maccari F, Arseni P, Chiodi. Levels of carnitines in brain and other tissues of rats of different ages: effect of acetyl-L-carnitine administration. Exp Gerontol. 1990;25(2):127-34.

18- Nascimento MA, Higa E, de Mello MT, Tufik S, Oyama LM, Santos RV, et al. Effects of short-term l-arginine supplementation on lipid profile and inflammatory proteins after acute resistance exercise in overweight men. Clin Nutr Espen. 2014;9(3):141-5.

19- Ali SA, Faddah L, Abdel-Baky A, Bayoumi A. Protective effect of L-carnitine and coenzyme Q10 on CCl4-induced liver injury in rats. Sci Pharm. 2010;78(4):881-6.

20- Heo YR, Kang CW, Cha YS. L-Carnitine changes the levels of insulin-like growth factors (IGFs) and IGF binding proteins in streptozotocin-induced diabetic rat. J Nutr Sci Vitaminol. 2001;47(5):329-34.

21- Irat AM, Aktan F, Ozansoy G. Effects of L-carnitine treatment on oxidant/antioxidant state and vascular

$$
\begin{aligned}
& \text { و استيل الكارنيتين افزايش يابد و مينان هماندان هموكلوبين كليكه } \\
& \text { اندازهيرى شود. }
\end{aligned}
$$

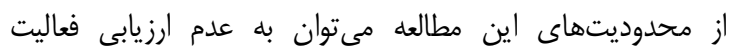

$$
\begin{aligned}
& \text { آنزيمهاى آنتىاكسيدانى كبد مانند سويراكسيدديسموتاز، كاتالاز و و ماني }
\end{aligned}
$$

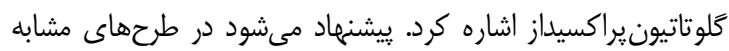

$$
\begin{aligned}
& \text { آتى، شاخصهاى مرتبط با استرس اكسيداتيو در سرم و بافتهاى } \\
& \text { كبد و مغز بررسى شود. }
\end{aligned}
$$

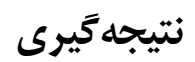

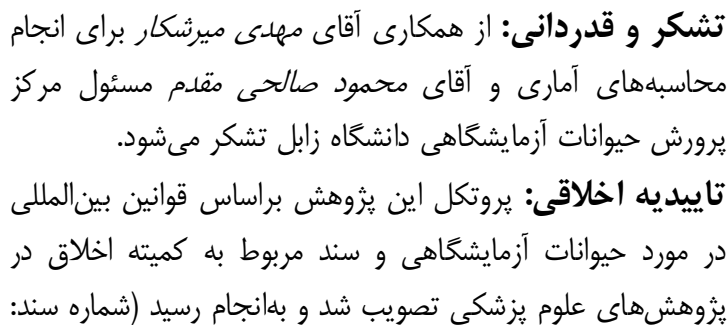
(BP-QP-106-01

تعارض منافع: هيج گونه تعارض منافع توسط نويسندگان بيان نشده است. منابع مالى: اين مطالعه براساس پاياننامه دكتراى حرفهاى خانم

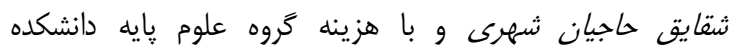
داميزشكى دانشگاه زابل انجام كرفت.

\section{منابع}

1- Carlsson PO, Schwarcz E, Korsgren O, Le Blanc K. Preserved $\beta$-cell function in type 1 diabetes by mesenchymal stromal cells. Diabetes. 2015;64(2):58792.

2- Panchal SK, Poudyal H, Ward LC, Waanders J, Brown L. Modulation of tissue fatty acids by L-carnitine attenuates metabolic syndrome in diet-induced obese rats. Food Funct. 2015;6(8):2496-506.

3- Parandak K, Arazi H, Khoshkhahesh F, NakhostinRoohi B. The effect of two-week l-carnitine supplementation on exercise-induced oxidative stress and muscle damage. Asian J Sports Med. 2014;5(2):1238.

4- Kobayashi A, Masumura Y, Yamazaki N. L-Carnitine treatment for congestive heart failure: Experimental and clinical study. Jpn Circ J. 1992;56(1):86-94.

5- Cruciani RA, Dvorkin E, Homel P, Culliney B, Malamud $\mathrm{S}$, Shaiova L, et al. L-carnitine supplementation for the treatment of fatigue and depressed mood in cancer patients with carnitine deficiency: A preliminary analysis. Ann NY Acad Sci. 2004;1033:168-76.

6- Rahimi R, Nikfar S, Larijani B, Abdollahi M. A review on the role of antioxidants in the management of

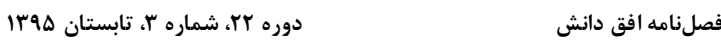




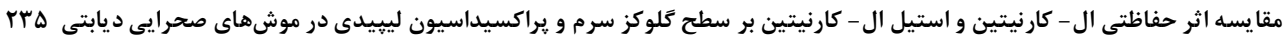

enhances $\mathrm{Na}\left({ }^{+}\right), \mathrm{K}\left({ }^{+}\right)$-ATPase glutathione-S-transferase and multiple unit activity and reduces lipid peroxidation and lipofuscin concentration in aged rat brain regions. Neurosci Lett. 2001;301(1):1-4.

25- Kathirvel E, Morgan K, French SW, Morgan TR. Acetyl-L-carnitine and lipoic acid improve mitochondrial abnormalities and serum levels of liver enzymes in a mouse model of nonalcoholic fatty liver disease. Nutr Res. 2013;33(11):932-41.

26- Aydogdu N, Atmaca G, Yalcin O, Taskiran R, Tastekin E, Kaymak K. Protective effects of L-carnitine on myoglobinuric acute renal failure in rats. Clin Exp Pharmacol Physiol. 2006;33(1-2):119-24. reactivity of streptozotocin-diabetic rat aorta. J Pharm Pharmacol. 2003;55(10):1389-95.

22- Fernandez I, Tonietti M, Camberos MDC, Bergada I, Schenone A, et al. Acetyl-L-Carnitine and nicotinamide for prevention of type 1 diabetes, I-literature review which gave support to the treatment, II-case report, evaluation of five years treatment. Immunome Res. 2015;11(2):094.

23- Hino K, Nishikawa M, Sato E, Inoue M. L-carnitine inhibits hypoglycemia-induced brain damage in the rat. Brain Res. 2005;1053(1-2):77-87.

24- Kaur J, Sharma D, Singh R. Acetyl-L-carnitine 